\title{
LA SOCIOLOGÍA DE LA MÚSICA. TEORÍAS CLÁSICAS Y PUNTOS DE PARTIDA EN LA DEFINICIÓN DE LA DISCIPLINA
}

\author{
SOCIOLOGY OF MUSIC. CLASSICAL THEORIES AND STARTING POINTS \\ IN THE DEFINITION OF DISCIPLINE
}

Jaime Hormigos Ruiz

Universidad Rey Juan Carlos, Madrid. España/Spain jaime.hormigos@urjc.es

Recibido/Received: 30/05/2012

Modificado/Modified: 12/09/2012

Aceptado/Accepted: 11/10/2012

\section{RESUMEN}

La música es una forma de percibir el mundo y un potente instrumento de conocimiento que contribuye a la construcción social de la realidad. Desde esta perspectiva, la sociología siempre ha mostrado un especial interés por su estudio analizando los procesos de interacción entre el hecho musical y sociedad, analizando especialmente las diversas formas de interacción que surgen en esta relación. El objetivo de este trabajo de investigación es exponer las principales teóricas clásicas que han dado lugar a la construcción de la sociología de la música, de este modo, se plantean las principales aportaciones de los trabajos de G. Simmel, M. Weber y Th. W. Adorno como punto de partida para concluir con un primer acercamiento teórico a la definición de la disciplina.

\section{PALABRAS CLAVE}

Sociología de la música, teorías sociológicas clásicas, Georg Simmel, Max Weber, Theodor. W. Adorno.

\section{SUMARIO}

1. Música y sociedad. 2. Georg Simmel y los estudios psicosociales de la música. 3. Max Weber y la racionalización del discurso musical. 4. Theodor W. Adorno y la sociología de la música como crítica social. 5. Conclusiones. Hacia una definición de la sociología de la música. Bibliografía.

\begin{abstract}
Music is a means of perceiving the world and an instrument of knowledge. Music contributes to the social construction of reality and sociology has always shown a special interest in its study. The current sociological studies of music analyze the process of interaction between music and society, taking in account particularly the various forms of attitude arising in this connection. This paper research analyzes the sociological theories of G. Simmel, M. Weber, and Th. W. Adorno as starting point to build the theoretical sociology of music.
\end{abstract}

\section{KEYWORDS}

Sociology of music, classical sociological theory, Georg Simmel, Max Weber, Theodor W. Adorno. 


\section{CONTENTS}

1. Music and Society. 2. Georg Simmel and psychosocial studies of music. 3. Max Weber and the rationalization of musical discourse. 4. Theodor W. Adorno and sociology of music as social criticism. 5. Conclusions. Definition of the sociology of music. References

\section{MÚSICA Y SOCIEDAD}

La música forma parte de nuestro día a día, siempre nos ha acompañado, es uno de los rituales más antiguos de la especie humana. No se sabe muy bien cómo y porqué el hombre comenzó a hacer música pero sí está claro que la música es un medio para percibir el mundo y un potente instrumento de conocimiento. No hay vida cotidiana sin música. Desde que nacemos estamos acostumbrados a que las melodías y canciones se interioricen en nuestra memoria, sonoricen nuestros recuerdos, y actúen por sí solas desencadenando emociones que nos unen al imaginario colectivo. Las diferentes culturas han logrado ordenar el ruido y crear melodías, ritmos y canciones que han desempeñado un papel trascendental en el desarrollo de la humanidad, desde los cantos de los pueblos primitivos hasta los ritmos más urbanos como el rock, el jazz o el blues han tenido una repercusión muy importante en el desarrollo de la sociedad. Por tanto partimos de la idea de que la música se ha dotado desde un principio de una carga inherente de sociabilidad, es expresión de la vida interior, expresión de los sentimientos, pero a su vez exige por parte de quienes la escuchan, receptividad y conocimiento del estilo de que se trate, además de conocimiento de la sociedad en la que se crea, ya que cada obra musical es un conjunto de signos, inventados durante la ejecución y dictados por las necesidades del contexto social. Si desligamos a la obra de la sociedad que la creó los signos musicales tendrán sentidos distintos.

La música constituye un hecho social innegable, presenta mil engranajes de carácter social, se inserta profundamente en la colectividad humana, recibe múltiples estímulos ambientales y crea, a su vez, nuevas relaciones entre los hombres. Las canciones y melodías que llevamos dentro de nuestro equipaje cultural implican determinadas ideas, significaciones, valores y funciones que relacionan íntimamente a los sonidos con el tejido cultural que los produce. La música es una experiencia colectiva, pero en la actualidad es habitual que olvidemos esta dimensión ya que estamos demasiado acostumbrados a escucharla en solitario. Este es el motivo por el que, en demasiadas ocasiones, queda desprovista de cualquier forma de interacción social. Pero esto no ha sido siempre así, hasta hace relativamente poco, el contacto del individuo con la música se producía en el directo, compartiendo la experiencia musical con otros y generándose, de este modo, un verdadero acontecimiento social (Drösser, 2012).

Desde el análisis sociológico podemos afirmar que la experiencia musical genera campos de actividad cultural, desempeñando un papel activo y social. Todas las funciones de la música son determinadas por la sociedad, por tanto, podemos decir que únicamente conoceremos la música y los movimientos sociales que hay en torno a ella, si conocemos el trasfondo cultural en el que se crea, ya que cada cultura musical está compuesta de sus propias peculiaridades y tiene establecidos procedimientos concretos para validar la música, para desplazar los límites de lo que se incluye y lo que se excluye como parte de un género o para crear etiquetas que ayuden a la interpretación y clasificación del sonido. Desde esta perspectiva el interés por el producto musical en sí se pierde, cobrando, en su lugar, especial relevancia el análisis de los aspectos dinámicos de la cultura que influyen en la composición 
musical. Así se presta especial atención al análisis de determinados aspectos extramusicales (función, simbolismo, cambio de actitudes y valores, enculturación, etc.) que se vuelven imprescindibles para comprender el universo sonoro contemporáneo.

El estudio de la música ha sido una constante en el pensamiento sociológico de todos los tiempos. El hecho musical se revela como una parte importante del mundo simbólico del ser humano, es participación e interacción. Como actividad simbólica que es, ha de ser vivida y experimentada socialmente para que se puedan verificar su realidad, su eficacia y su poder comunicativo. El sonido posee valores rituales, simbólicos, terapéuticos, mágicos, etc., que se han sedimentado en las expresiones musicales originales de cada grupo o comunidad. Para descifrar el mensaje que posee toda composición musical es necesario entender su estructura y la forma de la música, estructura y forma que quedan determinadas por las características de la sociedad que las crea, las hereda o las interpreta. Por tanto, el hecho musical debe entenderse como una actividad social.

Ahora bien, el estudio sociológico de la música presenta una gran complejidad ya que cada forma de sociedad, cada cultura, cada grupo, cada individuo entiende o busca algo distinto en la música, lo que genera una gran diversidad de puntos de vista a la hora de enfocar el objeto de estudio sociológico. Esta investigación pretende dirimir el punto de partida del estudio sociológico de la música a partir de observar las líneas de trabajo de varios teóricos sociales que establecieron la idea básica de presentar a la sociología como una herramienta útil para estudiar el papel que ocupa la música en la sociedad. Para ello intentamos establecer aquí las líneas generales que han marcado el pensamiento sociológico sobre la música para, a partir de su estudio, poder definir unas bases teóricas de la sociología de la música que permitan desarrollar más la disciplina.

\section{GEORG SIMMEL Y LOS ESTUDIOS PSICOSOCIALES DE LA MÚSICA}

Simmel dedicó varios de sus ensayos al estudio sociológico de la música, si bien no fue este su único enfoque analítico. Desde la etnología comparativa, consideró a la música como el arte menos mediado por el entendimiento en el que puede darse un tránsito directo entre los sentimientos del músico, la música y los sentimientos del oyente. En su ópera prima, Estudios psicológicos y etnológicos sobre música (1882), realiza un estudio del hecho musical desde una vertiente eminentemente social, centrándose en el papel que ocupan la melodía y el ritmo en la vida cotidiana de las sociedades. Su punto de partida es la necesidad de descubrir el sentido profundo de la música en su estado original, descubrir cómo y porqué el individuo se adueña de ella para utilizarla en distintos contextos y situaciones. Para poder responder a esta cuestión de fondo es necesario analizar los usos y funciones de la música, ya que el hecho musical, bien sea el acto de escuchar, componer, o ejecutar, es parte de la condición originaria del hombre, surge naturalmente de nuestros sentimientos y vivencias generando sonidos que pueden expresar algo al individuo que la escucha. Ahora bien, como exteriorización de nuestros sentimientos internos, necesita ser también una práctica social, y es precisamente ahí, en su relación con la sociedad, donde la música toma fuerza.

La investigación de Simmel amplía el discurso sobre la relación entre cultura y música. De este modo nos muestra cómo el discurso musical de una época se impregna del carácter y las características de los pueblos que la practican, de ahí la relación que establece entre la música y las esferas anímicas del amor, la mística, la ideología o el trabajo. Desde su perspectiva, podemos ver la clara dimensión social que posee la música en el hecho de que aparece como 
un complemento del desarrollo del lenguaje hablado, y este es una manifestación de las relaciones sociales. La música surge naturalmente de la elevación que los afectos producen sobre nuestros actos de habla y sobre nuestros movimientos, es expresión de las más variadas sensaciones anímicas. Así, se produce un tránsito del habla al canto, vehiculizado por la elevación espiritual que constituyen los diversos afectos: de ira, de alegría, de tristeza, etc. La música instrumental surge espontáneamente de las palmas, del choque rítmico de las manos, y luego de los instrumentos que ellas sostienen. El baile surge de los pasos, de las pisadas al compás. Teniendo en cuenta esto, Simmel nos enseña que el canto, el baile y la música instrumental surgen naturalmente de los sentimientos más universales y más vehementes: de un estado de alegría o de tristeza, lo que nos puede llevar a pensar que todos somos músicos preexistenciales, ya que existe una relación entre el hablar y el caminar y el cantar y el bailar. Se trata sólo de oír el ritmo y la melodía de nuestros estados anímicos.

Ahora bien, en este punto Simmel aboga por resolver el conflicto entre la idea de la universalidad de la música ya que no todas las músicas son iguales, ni todas las sociedades producen un ritmo similar o disponen de los mismos instrumentos musicales. El sociólogo explicaría estas diferencias argumentando que cada pueblo se beneficia de la música de un modo característico, y se sirve de ella en las diferentes esferas del trabajo, del amor, de la guerra y de la mística. Por estas prácticas, que son diferentes en cada contexto social, se experimenta un desarrollo desigual de la música y de los artefactos que se utilizan para su interpretación. El músico, a la hora de componer, se verá influenciado por la herencia musical de su sociedad. La historia de la música presenta casi continuamente el fenómeno de que cada compositor se para sobre los hombros de sus antecesores, eso reside implícitamente en que la suma total del desarrollo musical de su pueblo hasta un cierto momento es el fundamento de su formación musical, y tanto debe él a la cadena de sus antecesores, que sin ellos nunca habría devenido esto que es (Simmel, 2003:12).

\section{MAX WEBER Y LA RACIONALIZACIÓN DEL DISCURSO MUSICAL}

Hoy sabemos que la preocupación por los temas musicales siempre estuvo presente en la obra weberiana, y sobre todo, que esta preocupación ocupó un lugar principal en la trastienda de sus intereses. Sin embargo, debemos saber buscar en sus obras las referencias a este tema ya que, aparte de en el célebre ensayo sobre Los fundamentos racionales y sociológicos de la música (1921), no es fácil encontrar alusiones al tema. Podemos encontrar referencias a la música en sus estudios sobre la cultura o la religión. La sociología de la música de Weber ha quedado oculta ante la enorme pluralidad de áreas de estudio que desarrolló y, quizá por esto, se la considera a menudo como algo secundario en su pensamiento, pero a la hora de establecer las bases teóricas que sustenten a la sociología de la música como disciplina propia y autónoma nuestro punto de partida debe estar en las teorías del gran sociólogo alemán, tanto por su alto grado de conocimiento metodológico, como filosófico. Weber fue uno de los primeros en ver la riqueza que suponía el acercamiento al estudio del hecho musical desde la perspectiva sociológica. A pesar de haber pasado de puntillas por el tema, dejando únicamente algunas páginas dedicadas a la música, hoy sus teorías constituyen una referencia ineludible. La originalidad de su planteamiento está en la búsqueda de la racionalidad en la música que a simple vista aparece como algo irracional.

En Los fundamentos racionales y sociológicos de la música (1921), nos explica que la historia de la música debe entenderse a partir de la influencia de factores externos, pero 
también de factores derivados de la lógica musical, para ello traza un camino muy lineal que nos lleva desde las teorías musicales primitivas, que se basan en una resolución fisiológica o psicológica de momentos de tensión, a la elaboración de una música cada vez más racional, en el sentido en el que adapta sus medios a sus fines. El sociólogo alemán señala que hasta un terreno de experiencias tan interno, y al parecer subjetivo, como el de la música, puede ser tratado sociológicamente con arreglo a su concepción de la racionalización. Así pues, ve la fijación de modelos sonoros por medio de un sistema concreto de signos, el establecimiento de las escalas bien temperadas, etc., como un síntoma de racionalización progresiva. Weber parte, para establecer sus líneas de investigación, de la existencia de una relación o paralelismo entre el desarrollo de la sociedad y el de la música que se verifica al nivel de las estructuras lingüísticas. Es por ello que para desarrollar este presupuesto se centra en un análisis de la historia del lenguaje musical más que de la historia de la propia música. Considera que la música occidental se ha desarrollado en una dirección peculiarmente racional que la distingue de otras músicas. Este proceso de racionalización reduce al hecho musical a procedimientos rutinarios basados en principios comprehensivos. Así, en el mundo occidental se ha experimentado una transformación del proceso de producción musical que la ha convertido en un asunto calculable que opera con medios conocidos, con instrumentos efectivos y reglas comprensibles, lo que facilita su estudio, análisis y circulación.

La teoría weberiana defiende que la evolución de la música, como la de la sociedad, se produce dentro de unas categorías conceptuales exactas, que vinculan el progreso o evolución musical con el de la sociedad dentro de unos caminos muy concretos. El elemento técnico está absolutamente indiferenciado del proceso creativo. La transformación sonora de la música europea occidental tuvo en la tecnología uno de sus pilares básicos ya que fue la imprenta de Gutenberg, junto con las nuevas técnicas que aparecen a finales de la Edad Media en la construcción de instrumentos de cuerda, los principales hechos que determinan la evolución del discurso sonoro occidental. Posteriormente, con la organización gremial de los músicos en el siglo XVIII, se proporciona la aparición de trabajos fijos en las orquestas de las cortes y municipios quedando la actividad del músico reconocida socialmente. Las exigencias técnicas generan procedimientos racionales de creación sonora en una dialéctica mutua inseparable.

Siguiendo estas premisas, Weber llega a un estudio evolutivo del lenguaje musical, concluyendo que este no se cierra en sí mismo, sino que nace en conexión con una serie de acontecimientos que no son solamente musicales, nace en conexión con las exigencias de comunicación musical de una determinada sociedad y con la progresiva extensión de la racionalización de los lenguajes y de las relaciones sociales. Considera la música como una forma de comunicación, impersonal y anónima, cuyo desarrollo se inserta con múltiples nexos dentro de un proceso más amplio de racionalización que afecta a las estructuras sociales y económicas y que tiene su punto culminante en la expansión del sistema temperado en la época de la aparición del capitalismo industrial. Ahora bien, para que la música tenga el poder de comunicar es necesario ponerla en contacto con la sociedad. Sólo bajo esas condiciones se podrá definir la música como acción social.

La sociología de la música de Weber no considera el valor estético de la música, sino los diversos condicionamientos entre la música y la sociedad dentro del marco de una ley formal reguladora de la evolución de la estructura interna de ambas. La aproximación al hecho musical desde la sociología weberiana resulta especialmente importante en tanto que abre las puertas a una sociología racional y estructural, al hacerse tangible el vínculo que se establece entre la música y la sociedad, en el ámbito estructural interno, y no como una serie fragmentada de condicionamientos de diferentes naturalezas. Sin embargo, la teoría 
weberiana deja una serie de elementos muy importantes sin analizar, quizá porque su obra quedó inacabada, nos referimos al estudio de la dimensión simbólica de la música, la relación entre la música y la ideología, la recepción musical o el tema de la contribución social del valor estético. Aspectos todos estos que la sociología acometerá más adelante en la obra de otros importantes autores.

\section{THEODOR W. ADORNO Y LA SOCIOLOGÍA DE LA MÚSICA COMO CRÍTICA SOCIAL}

Si hay un autor que merece un puesto especial a la hora de hablar de la sociología de la música ese es Th. W. Adorno. Hoy en día resulta difícil analizar la problemática ideológica, filosófica, sociológica y estética que emerge de la música contemporánea sin tener en cuenta su pensamiento. Nadie ha estudiado con tanta profundidad y agudeza como lo hizo él, los nexos que liga y, dialécticamente, estrecha a la música con el mundo de la ideología y es precisamente por esto por lo que la obra de Adorno se diferencia radicalmente de toda la sociología de la música anterior y supone un nuevo punto de partida. Aquí, se toman aquellas ideas que nos ayudan a nuestra tarea, la construcción de una sociología de la música actual.

Los estudios de Adorno parten de los enfoques de la teoría marxista a la que criticará por considerar que establece una imagen simplista que presenta a la obra musical como un reflejo de la estructura económica de la sociedad en la que se crea. El objetivo de su obra no es solo la crítica de la música, sino también la de la sociedad. Su aportación supera las limitaciones marxistas para tomar en consideración el auge y los efectos de la tecnología y de la organización económica moderna que permite el desarrollo de la cultura de masas $\mathrm{y}$, en consecuencia, la creación de una audiencia de masas. Sostiene que si bien el arte debería ser un fin en sí mismo, en todos los niveles, se hace un uso insidioso de él para reforzar la falsa conciencia del público. Sus estudios parten siempre de la obra en sí y de la estructura musical de que ésta hace gala, al objeto de concretar cómo en la misma se deposita, se estructura y toma forma la ideología. Esta actitud no compromete la autonomía de la obra de arte, pese a que el carácter social del arte y su autonomía parecen contradecirse recíprocamente; pero sucede que, justamente, uno de los rasgos más definitorios de la sociología de la música de Adorno consiste en dilucidar los puntos de contradicción dialéctica con el fin de poner en evidencia las fracturas internas del pensamiento y de la realidad. Adorno establece un análisis del hecho musical que no se cierra en la mera descripción de la música en sí misma.

En Filosofía de la nueva música (1948), Adorno se centra en el análisis de la música contemporánea, intentando demostrar que, en la sociedad capitalista avanzada, la única vía de supervivencia de que dispone la música consiste en ser la antítesis de la sociedad, conservando así su verdad social gracias al aislamiento y esto a la larga la vuelve árida, termina restringida a pequeños grupos de mentalidad avanzada. Es como si se la substrajera al estímulo productivo o, dicho de otro modo, a la propia razón de ser. "Las únicas obras que cuentan, son las que ya no son obras" (Adorno, 1966:38). Haciendo mención a la depravación del arte musical en una sociedad regida por las leyes que impone la creciente cultura de masas, observa como la música, que es por naturaleza expresiva y comunicativa como todas las artes, pierde toda posibilidad de expresión y todo poder de comunicación, puesto que la sociedad de masas industrial, comercializa toda forma de comunicación volviéndola trivial, alienándola y transformándola en una cosa, en un producto de cambio, en un fetiche; en esta situación, quizá el aislamiento y el silencio sean las únicas armas del 
músico que quiera conservar en su obra el carácter de verdad o, al menos, el testimonio de la angustia en la que vive el hombre contemporáneo. Toda la actividad comunicativa y revolucionaria de la música peligra si ésta se convierte en una mercancía, en una actividad regulada por las relaciones económico-sociales. Si el arte musical acepta estos cambios y se reduce a un simple juego, entonces habrá de renunciar a la verdad, perdiendo en tal caso el único derecho que tenía a la existencia. La música para volver a tener poder de comunicación, para evitar estar corrompida y alterada, debe ignorar los presupuestos de la sociedad que la coloca en el centro del universo creado por las industrias culturales.

Uno de los núcleos capitales del pensamiento de Adorno, de mayor interés a nivel teórico, es la relación que establece entre la música y la sociedad. Esta relación que, analizada desde la perspectiva marxista resulta demasiado simple, es considerada por Adorno como algo muy complicado que para su comprensión debe incluir necesariamente un discurso acerca del valor estético de la obra. En realidad, el valor estético no es algo que se añada o se superponga al valor comunicativo y social del lenguaje musical, sino que es un hecho social en sí. Debido a esto la relación música-sociedad es extremadamente problemática porque entre ambas no se da una relación de causa-efecto; la música es un hecho social porque está en la sociedad y, por lo tanto, lo verdaderamente importante será conocer cuál es la función o funciones de la música dentro de la sociedad. La sociedad se define en música de forma extremadamente indirecta y mediata, por lo que la obra de arte no debe ser coherente necesariamente con las estructuras de la realidad. Por el contrario, cuanto más auténtico es su valor estético, tanto más problemática, contradictoria y compleja será su relación con la realidad. La música, en ningún caso, ejerce una función preestablecida socialmente; sin embargo, desde el momento en que existen tantos tipos diferentes de música y de sociedades, la tarea del sociólogo de la música habrá de consistir en determinar que funciones desempeña esta dentro de las diferentes sociedades.

Adorno intenta incorporar todos estos componentes a una comprensión total de la forma musical y su relación con la sociedad. Para ello parte de la idea de que la música y la sociedad no se encuentran en una relación de dependencia directa y, por supuesto, desde su punto de vista, la música no es un espejo de la sociedad. En realidad, la música mantiene una relación tanto más directa con la sociedad cuanto menos auténtica sea. Con esta afirmación Adorno vuelve a anticiparte a su tiempo y nos hace ver como realmente la obra que queda ligada estrechamente a la sociedad es aquella que ha sido manipulada por la estructura social, creada a su imagen y semejanza, aquella que ha sido construida por la cultura de masas para su fácil comercialización. La música que consigue escapar de las garras de la cultura manufacturada, será una obra auténtica pero tendrá que pagar el precio de no tener nada que ver con la sociedad, de verse marginada, apartada, entendida únicamente por una minoría que debe aprender a valorarla. Esto no significa que la obra auténtica escape al análisis sociológico o que no posea relación alguna con la sociedad, sino que, al ser auténtica, la obra vuelve tal relación mucho más problemática y dialéctica. La obra musical auténtica y autónoma no realiza un valor estético al margen de la sociedad, sino que representa prioritariamente un valor en oposición a la sociedad constituida.

Otra teoría importante, dentro del análisis sociológico de la música que establece el teórico alemán, es la que parte de la idea de que en toda música, aunque menos en su lenguaje que en su interna conexión estructural, se manifiesta, en calidad de antagonista, la sociedad en su totalidad. La música tiene mucho que ver con las clases sociales, en la medida en que en ella se imprime a fondo la relación de clases. La música contiene, en menor o en mayor cantidad, ideología según el grado de conciencia objetiva implícito en ella. "El arte, en general, y la 
música, en particular, no son el reflejo pasivo de un estado de hecho. En su relación dialéctica con la realidad, el arte no debe garantizar o reflejar la paz y el orden, sino que debe forzar la aparición de cuanto se quedó bajo la superficie, resistiendo así la opresión de ésta, de la fachada" (Adorno, 1948:35). La música puede asumir una función estimulante dentro de la sociedad; puede denunciar la crisis y la falsedad vigentes en las relaciones humanas y desenmascarar el orden constituido. La música es algo semejante al lenguaje, pero no es un lenguaje. Tiende al fin de un lenguaje desprovisto de intenciones. La música, carente de todo pensamiento absoluto, dejaría de ser música y devendría impropiamente lenguaje.

En la Introducción a la sociología de la música (1975) encontramos otro tema novedoso que se va a convertir en un importante punto de referencia para otros sociólogos posteriores, nos referimos a su particular tipología jerárquicamente ordenada de los oyentes de música. Mediante un análisis de la conducta típica del acto de escuchar extrae conclusiones concernientes al significado cambiante de la escucha al ubicarla en sus contextos históricos y tecnológicos. Rastrea las funciones cambiantes de la música, contrastando su papel como arte en oposición al entretenimiento, la publicidad, hacer ruido o la decoración. Adorno demuestra que no todo el mundo recibe la música de la misma manera, sino que hay condicionantes sociales importantes (formación musical, formas de recepción, pautas de consumo de la sociedad, etc.), que influyen en la percepción musical. Así establece una tipología de oyentes que oscilan entre los expertos casi profesionales hasta los más pasivos, las masas inexpertas.

Terminamos este repaso a la sociología de la música de Adorno trayendo otra de las muchas "profecías" que encontramos en sus obras y que tienen cabida en la sociedad actual y no pueden pasar desapercibidas para el sociólogo. Para Adorno, en una sociedad donde incluso la actividad intelectual se expone a ser completamente dominada e inundada por las relaciones económico-sociales, en las que el individuo está alienado debido a que el sistema capitalista ha terminado con la autonomía y la libre creatividad a base de producir una estandarización que ha implicado al arte hasta degradarlo a la categoría de producto comercial, sujeto a las leyes de la oferta y la demanda. En esta sociedad, que se parece demasiado a la actual, la música corre el peligro de verse convertida en mercancía, de ser profanada, de perder su carácter de verdad para quedar reducida a un simple juego.

\section{CONCLUSIONES. HACIA UNA DEFINICIÓN DE LA SOCIOLOGÍA DE LA MÚSICA}

A partir de las teóricas expuestas en esta investigación, podríamos definir a la sociología de la música como aquella disciplina que estudia el hecho musical partiendo de la idea de que éste se presenta como un fenómeno social, de este modo, para comprender el sentido y significado del discurso musical de una época deberemos analizar todos los aspectos sociales que rodean a la música. El enfoque sociológico nos permitiría estudiar los factores sociales que rodean al hecho musical desde su creación hasta la puesta en escena, pasando por la interpretación o la distribución. Por sociales entendemos (Noya, 2011) variables estructuralesposicionales (clase social, género, etc.), relacionales (redes sociales, patrones de interacción) o culturales (valores, símbolos). Por tanto, para definir sociológicamente el hecho musical tendremos que volver a un momento de percepción tangible, es decir, al estudio del hecho social generado por la música, ya sea este hecho subjetivo en el sentido de Weber u objetivo en el de Simmel o Adorno, y ya sea que se contemple la obra, en términos de creación, 
interpretación o consumo, desde dentro o desde fuera. El objeto central de estudio para el sociólogo de la música no es la música en sí misma, que puede ser conceptualmente analizada y tratada como estructura, sino la relación que esta música crea entre el individuo y la sociedad. De esta forma, podemos observar que en la relación aparecerán maneras de actuar, pensar y sentir exteriores al individuo que permiten a la música generar experiencias y valores compartidos, así como, a través de tensiones generadas por la cultura y la acción social subyacente, símbolos expresivos compartidos que van a formar parte del proceso de interacción musical contribuyendo a facilitar la comunicación entre música y público, organizando el proceso de interacción y regulando normas de apreciación del discurso musical que se irán adaptando a las necesidades sociales del momento.

No hay duda de que el hecho musical debe entenderse como una actividad social y, de este modo, la sociología aparece como una disciplina necesaria para ordenar el actual repertorio musical y ponerlo en relación con el contexto social contemporáneo para observar como es, precisamente, este contexto el que dota de valor y funcionalidad al hecho musical. Sociológicamente sólo puede captarse la música en el momento en que se expone la relación artista-oyente, cuando la obra musical llama al exterior, donde provoca un momento trascendental. Teniendo en cuenta este presupuesto, decimos que la sociología de la música se ocupará de averiguar cuáles son las formas esenciales de la actividad musical en un tipo de sociedad y en un tiempo determinado, y cuáles son los grupos sociales específicos que se reúnen en torno a una forma musical concreta. Por otro lado, si consideramos a la música como un proceso social vivo y actual, la sociología de ésta, debe estudiar la interrelación que se produce entre música y sociedad, teniendo especialmente en cuenta las diversas formas de actitud que se derivan de dicha interrelación.

El desarrollo de las teorías sociológicas clásicas expuestas en el presente artículo supone el punto de partida básico para comenzar el estudio del paralelismo que existe entre el desarrollo de la sociedad y el de la música. La evolución de la música, como la de la sociedad, se produce dentro de unas categorías conceptuales exactas, que vinculan el progreso o evolución musical con el de la sociedad, dentro de unos caminos muy concretos. De este modo, los primeros acercamientos sociológicos al tema se centran en el estudio del lenguaje musical, concluyendo que este no se cierra en sí mismo, sino que nace en conexión con una serie de acontecimientos que no son solamente musicales, nace en conexión con las exigencias de comunicación musical de una determinada sociedad y con la progresiva extensión de la racionalización de los lenguajes musicales y de las relaciones sociales. Muchos de estos primeros acercamientos sociológicos a la música carecen de perspectiva sociológica para perderse, únicamente, en el estudio de la estética musical, descuidando su perspectiva social. La forma de unir estos enfoques teóricos sobre la estética musical al objeto de estudio de la sociología de la música es considerar que el valor estético es también un valor social, y por tanto, es inútil acercarse a la dimensión estética de la música con otras orientaciones que prescindan de la sociología, ya que, cualquier otra aproximación será inadecuada para explicar todo lo que engloba el fenómeno musical. Cuando el músico está creando una melodía o una canción, por muy bella que esta resulte, no tiene nada de social, es necesario poner esa música al servicio de una sociedad para comprobar qué sentimientos despierta, para analizar la sensación de la música, desde este punto de vista es posible incluir en el objeto de estudio a aquellos sonidos que quedarían muy alejados del campo de análisis de la estética musical tradicional por considerarlos carentes de belleza. Desde esta perspectiva, consideramos que la sociología de la música debe despojarse de toda esa dimensión valorativa que busca la crítica fácil del sonido, o la clasificación del hecho musical, nuestra disciplina debe intentar describir 
el paisaje sonoro que rodea al individuo. La música, sea del tipo que sea, siempre roza al hombre, en su casa, en el trabajo, por la mañana, por la noche, en su vida interior o en su vida social, individualmente o en grupo. La sociología de la música debe considerar a ésta como una esfera institucional que, por sus funciones tradicionales, extraordinariamente importantes, está en condiciones de lograr procesos de identidad social.

\section{BIBLIOGRAFÍA}

ADORNO, TH. W. (1948), Filosofía de la nueva música. Buenos Aires: Sur.

ADORNO, TH, W. (1966), Disonancias. Música en el mundo dirigido. Madrid: Rialp.

ADORNO, TH, W. (1975), Introducción a la sociología de la música. Madrid: Taurus.

BLAUKOPF, K. (1988), Sociología de la música. Madrid: Real Musical.

DRÖSSER, CH. (2012), La seducción de la música. Los secretos de nuestro instinto musical. Barcelona: Ariel.

FUBINI, E. (2000), La estética musical desde la Antigüedad hasta el siglo XX. Madrid: Alianza.

HORMIGOS, J. (2008), Música y sociedad. Análisis sociológico de la cultura musical de la posmodernidad. Madrid: Fundación Autor.

HORMIGOS, J. (2010), "Música, comunicación e identidad cultural", en Noya, J., Del Val, F. y Pérez Colman, C. M. (coords.) MUSYCA. Música, sociedad y creatividad artística. Madrid: Biblioteca Nueva. HORMIGOS, J. (2010), "Distribución musical en la sociedad de consumo. La creación de identidades culturales a través del sonido", en Comunicar, n 34 , pp. 91-98.

LUHMANN, N. (2008), El arte de la sociedad. Barcelona: Herder.

NOYA, J. (dir.)((2011), "Música y sociología” en Scherzo. Revista de Música, n 268, pp. 89-101.

RODRÍGUEZ MORATÓ, A. (1983), "La trascendencia teórica de la sociología de la música. El caso de Max Weber", en Papers. Revista de sociología, n² 29, pp. 9-61.

ROMERO FILLAT, J. M. (2011), M de música. Del oído a la alquimia emocional. Barcelona: Alba.

SILBERMANN, A. (1961), Estructura social de la música. Madrid: Taurus.

SIMMEL, G. (2003), Estudios psicológicos y etnológicos sobre música. Buenos Aires: Gorla.

SUPICIC, I. (1987), Music in society: A guide to the sociology of music. Nueva York: Pendragon Press.

WEBER, M. (1993), "Los fundamentos racionales y sociológicos de la música", en Economía y sociedad, Madrid, FCE, pp. 1118-1183.

ZOLBERG, V. L. (2002), Sociología de las artes. Madrid: Fundación Autor.

\section{Breve currículo:}

\section{Jaime Hormigos Ruiz}

Doctor en Sociología por la Universidad Pontificia de Salamanca. Ha impartido docencia en la Escuela Diplomática (Ministerio de Asuntos Exteriores y Cooperación de España), Universidad de Castilla-La Mancha y en el Centro Superior de Estudio Jurídicos y Sociales Ramón Carande (Universidad Complutense de Madrid). En la actualidad es profesor del Departamento de Ciencias Sociales de la Universidad Rey Juan Carlos de Madrid donde imparte las asignaturas de Sociología de la Música, Estructura Social y Sociología de la Empresa y de los Recursos Humanos. Sus líneas de investigación abarcan, entre otras, la sociología de la cultura y de la música, las industrias culturales, el multiculturalismo, las dimensiones sociales de la globalización o la sociología de la empresa. 